\title{
1 Mild CF Lung Disease is Associated with Bacterial Community Stability
}

2 Thomas H. Hampton ${ }^{\mathrm{a} 1}$, Devin Thomas ${ }^{\mathrm{b} 2}$, Christopher van der Gast ${ }^{\mathrm{c} 3}$, George A. O’Toole ${ }^{\mathrm{a} 4}(*)$, 3 and Bruce A. Stanton ${ }^{\mathrm{a} 5}(*)$

$4 \quad$ (*) Co-Corresponding authors

5 aDepartment of Microbiology and Immunology, Geisel School of Medicine at Dartmouth,

6 Hanover, New Hampshire, USA

7 bHubbard Center for Genomic Studies, University of New Hampshire, Durham, New Hampshire, 8 USA

9 'Department of Life Sciences, Manchester Metropolitan University, Manchester, UK

$11 \quad{ }^{1}$ Thomas.H.Hampton@Dartmouth.edu

12 2Devin.W.Thomas@gmail.com

13 32.vanderGast@mmu.ac.uk

14 4George.A.O'Toole.Jr@dartmouth.edu

$15 \quad{ }^{5}$ Bruce.A.Stanton@dartmouth.edu

17 Abstract

19 Microbial communities in the airways of persons with $\mathrm{CF}$ (pwCF) are variable, may include

20 genera that are not typically associated with CF, and their composition can be difficult to

21 correlate with long-term disease outcomes. Leveraging two large datasets characterizing sputum

22 communities of 167 pwCF and associated metadata, we identify five bacterial community types.

23 These communities explain $24 \%$ of the variability in lung function in this cohort, far more than

24 single factors like Simpson diversity, which explains only 4\%. Subjects with Pseudomonas-

25 dominated communities tended to be older and have reduced percent predicted $\mathrm{FEV}_{1}\left(\mathrm{ppFEV}_{1}\right)$

26 than subjects with Streptococcus-dominated communities, consistent with previous findings. To

27 assess the predictive power of these five communities in a longitudinal setting, we used random

28 forests to classify 346 additional samples from 24 subjects observed 8 years on average in a 
range of clinical states. Subjects with mild disease were more likely to be observed at baseline, was more self-similar over time, as measured by Bray-Curtis distance. Interestingly, we found that subjects with mild disease were more likely to remain in a mixed Pseudomonas community, providing some support for the climax-attack model of the CF airway. In contrast, patients with worse outcomes were more likely to show shifts among community types. Our results suggest that bacterial community instability may be a risk factor for lung function decline and indicates the need to better understand factors that drive shifts in community composition.

\section{Introduction}

Cystic fibrosis (CF) is a genetic disease affecting about 30,000 people in the United States and

4170,000 world-wide (1). It has long been recognized that airway infection by Pseudomonas aeruginosa predicts morbidity and mortality in young children with CF (2). Direct sampling of the CF airway demonstrates that a small set of established CF pathogens such as Pseudomonas aeruginosa, Staphylococcus aureus, Haemophilus influenzae and species from genera

CF (3). The prevalence of Pseudomonas infection in the CF community increases with age (4), and it has been reported that few pathogens other than Pseudomonas are detectable in end stage 
52 demonstrates that genera outside the established set of CF pathogens, such as Streptococcus, and

53 anaerobes like Prevotella and Veillonella also play important roles in lung disease for persons

54 with $\mathrm{CF}$ (pwCF) (10-12).

56 CF lung disease is now considered a polymicrobial phenomenon (13) that can be described using

57 ecological concepts like species diversity. Diversity has been associated with improved lung

58 function (14-17) but increased diversity may also signal the onset of exacerbation (18).

59 Longitudinal analysis, in which a pwCF is followed over time, generally reveals that the CF

60 airway microbiome as relatively stable (18-21) and changes modestly during cycles of antibiotic

61 treatment and pulmonary exacerbations, acute phenomena characterized by a rapid decline in

62 overall health, accompanied by decreased lung function $(19,22-24)$ during exacerbations pwCF

63 experience rapid decline in overall health frequently accompanied by permanently decreased

64 lung function (19). More frequent exacerbations, and failure to recover fully from these

65 exacerbations, are thought to differentiate people with moderate or severe disease from those

66 with mild CF lung disease $(26,27)$. Intravenous antibiotic treatment in a hospital setting is

67 recommended during a pulmonary exacerbation (20) and recovery usually occurs over a period

68 of weeks (21). Complete recovery of lung function to levels prior to exacerbation is more

69 common in younger pwCF (22) and those with fewer exacerbations. Recovery may be mediated

70 by response to antibiotics like tobramycin, which is at least partly predictable from polymicrobial

71 signatures (23). It is possible that some exacerbations are triggered by increasing relative

72 abundance of anaerobes in the two weeks leading up to an exacerbation (24) or by specific

73 species of Streptococcus, including anginosus group streptococci (AGS), also known as 
74 the milleri group streptococci (25-27). Collectively, recent findings paint a complex picture of

75 how exacerbations occur in $\mathrm{CF}$.

77 One model of how dynamic changes in the CF airway community might be associated with

78 changes in patient health suggests that the CF airway microbiome is normally a stable climax

79 community (28) dominated by a classic pathogen such as Pseudomonas, Achromobacter,

80 Staphylococcus. From time to time, the intrusion of facultative or obligate anaerobes, via an

81 undescribed mechanism, leads to a fermentative "attack community" that lowers $\mathrm{pH}$ and favors

82 further expansion of anaerobes (28). This population shift would increase bacterial species

83 diversity, consistent with the increased diversity during exacerbation that has been previously

84 observed (18). Interestingly, this is one instance where increased diversity is associated with a

85 worse clinical outcome, rather than better outcomes as is typically reported $(14,17,29,30,31)$.

86 Furthermore, this climax-attack model is also consistent with the concept of stable core and

87 dynamic satellite taxa (16) because these satellite taxa are largely the same genera that are

88 thought to constitute the attack community, and it has been shown that satellite genera are more

89 dynamic across disease states (32).

91 The primary aim of this study was to improve our understanding of the baseline community

92 types, including 1) identifying discrete CF airway community types, 2) assessing whether

93 community types are associated with different health outcomes, 3) describing how community

94 types in pwCF change over time, and 4) whether community stability is associated with disease

95 severity. This analysis included a variety of machine learning techniques applied to both cross-

96 sectional and longitudinal data sets. Collectively, our results are consistent with a recent report 
97 that bacterial communities in stable patients have less variation in community structure over time

98 (33), and our results support the climax-attack model of CF airway disease (28). In addition, we

99 identify a five-community model that accounts for $24 \%$ of the variability in lung function, far

100 more than any single factors explored previously.

101

102 Methods

103

104 Data processing. Publicly available 16S rRNA gene amplicon library sequence reads and

105 associated metadata from recent studies by Carmody et al. (PRJNA423040) (18) and

106 Cuthbertson et al. (PRJEB30646) (17) were downloaded from Bioproject

107 (https://www.ncbi.nlm.nih.gov/bioproject/). Reads in fastq format were mapped to unique

108 bacterial genera using QIME2 (34).

109

110 Cross-sectional data set: We assembled a cross-sectional data set by combining baseline data

111 (i.e., not exacerbating / receiving treatment for exacerbation) set from 167 unique pwCF, 84 from

112 the Cuthbertson et al. study (17) and 83 from the Carmody study (18). In those instances where

113 more than one baseline sample was available from a given subject, the first sample taken was

114 used, together with metadata (e.g. $\mathrm{ppFEV}_{1}$ ). The two data sets were similar, but not identical in

115 terms of age and lung function. The 84 subjects included in the cross-sectional data set from the

116 Carmody et al. (17) were slightly younger, with a mean age of $25.6 \pm 10.0 \mathrm{SD}$ compared to a

117 mean age of $30.27 \pm 10.9$ SD. OTU level mapping and metadata for the cross-sectional two data

118 sets $(17,18)$ is provided in Supplemental Table 1 
119 (https://doi.org/10.6084/m9.figshare.14261084.v1) and Supplemental Table 2

120 (https://doi.org/10.6084/m9.figshare.14261219.v1)

121

122 Longitudinal data set: The longitudinal data set was a subset of samples from the Carmody et

123 al. (18) study, specifically, 346 16S rRNA gene amplicon datasets from 24 subjects that were

124 observed at least 10 times. Age at time of sampling ranged from 11 to 54, with median of 27 and

125 an interquartile range of 8 . Lung function $\left(\mathrm{ppFEV}_{1}\right)$ of subjects in the longitudinal data set

126 ranged from 9 to $123 \%$, with a median of 50 and an interquartile range of 36 . Longitudinal

127 subjects are more fully described in Table 1. OTU level mapping and metadata for the

128 longitudinal data set (18) is provided in Supplemental Table 3

129 (https://doi.org/10.6084/m9.figshare.14261432.v1).

131 Statistical analyses. Data analysis was performed in R 4.0.1 (https://www.R-project.org/). Bray-

132 Curtis dissimilarity was calculated using ecodist (35). Simpson diversity was calculated with

133 vegan 2.5-7 (36). Clustering was performed using kmeans in base $\mathrm{R}$ and clusters were visualized

134 and gap analysis was performed using factoextra 1.0.7 (37). Random forests were generated

135 using randomForest 4.6-14 (38). Discrete Time Markov chains were determined using the

136 markovchain package 0.8.5-4 (39).

138 Results 
142 As the emphasis in CF airway microbiome investigation has shifted toward a polymicrobial

143 interpretation (13), data analysis has increasingly focused on multivariate comparisons. We

144 therefore began our analysis to identify polymicrobial community clusters by calculating Bray-

145 Curtis dissimilarity (40) between genus level taxonomic assignments in bacterial 16S rRNA gene

146 amplicon sequencing data from 167 sputum samples from people with CF. Bray-Curtis similarity

147 (40) is a common measure used to summarize the similarity between microbial communities, and

148 places a larger weight on species that are commonly observed, partly mitigating the problem of

149 random sampling errors associated with rare species. Samples for this analysis were chosen as a

150 cross sectional subset of two recently published studies $(17,18)$, and included clinically stable

151 subjects aged 8 to 69 from 14 CF centers in the US and Europe creating a snapshot that should

152 include many of the community types present in pwCF. We calculated the Bray-Curtis similarity

153 across 167 cross-sectional samples from these two independent studies: a cross-sectional study

154 from Cuthbertson et al. colleagues (17), from which 83 samples were analyzed, and a

155 longitudinal study by Carmody et al. (18), from which we selected a single representative sample

156 from each patient for this analysis (84 samples).

158 We next used k-means to cluster samples using the Bray-Curtis similarity matrix we generated

159 above. The k-means machine learning algorithm requires the user to identify how many clusters

160 (k) are to be identified in the data, then uses an iterative approach to assign samples to each

161 cluster to minimize distances between samples in the same cluster and maximize distances

162 between samples in different clusters. Such machine learning approaches are commonly applied

163 to microbiome studies (41). For example, unsupervised techniques like hierarchical clustering

164 (42) have been used to identify core taxa in the CF airway (16) and gut (43) and to demonstrate 
165 that samples from the same person tend to be similar to each other, even across disease and

166 treatment (44). K-means analysis has also been used to identify groups of patients with similar

167 patterns in inflammation, microbiota, or clinical factors (45). What makes k-means unsupervised

168 is that similarity between clusters is based only on observed data, in this case, counts of bacterial

169 genera. Unsupervised learning does not take sample labels (e.g., "severe disease" or

170 "exacerbation") into consideration. Therefore, when unsupervised clustering places samples

171 labeled "severe disease" together, it is likely that a non-random process (e.g., the result of a

172 biological difference) caused the samples to cluster.

174 As described above, the k-means algorithm requires the user to identify how many clusters (k)

175 are to be identified in the data. Since we had no prior information to justify a particular choice of

$176 \mathrm{k}$, we used another machine learning approach, the gap statistic (46), to estimate the number of

177 distinct clusters in our cross-sectional data. The gap statistic has recently been used to evaluate

178 the optimal number of clusters in CF airway microbiome data (29). The gap statistic identifies

179 the smallest value of $\mathrm{k}$ that minimizes distances between samples in the same cluster and

180 maximize distances between samples. Gap analysis suggested the existence of five distinct

181 community types in our cross-sectional data set of the 167 baseline samples analyzed here. We

182 found that subjects belonging to different communities also differed significantly in lung

183 function (see below); this finding suggests that clusters are based on biological differences (47)

184 and that community types may be clinically relevant. The optimal number of clusters (five)

185 chosen by the gap statistic algorithm is shown by the vertical dashed line in Figure 1A. The basis

186 of this choice is driven by the break in the data after $\mathrm{k}=5$. 
188 A principal coordinate analysis that captures $>70 \%$ of the variance of these data (Figure 1B)

189 shows how the clusters separate into 5 largely non-overlapping groups. It is important to note

190 that this analysis raises the possibility of alternative, potentially equally valid grouping of the

191 samples and/or potential overlap among these communities.

192

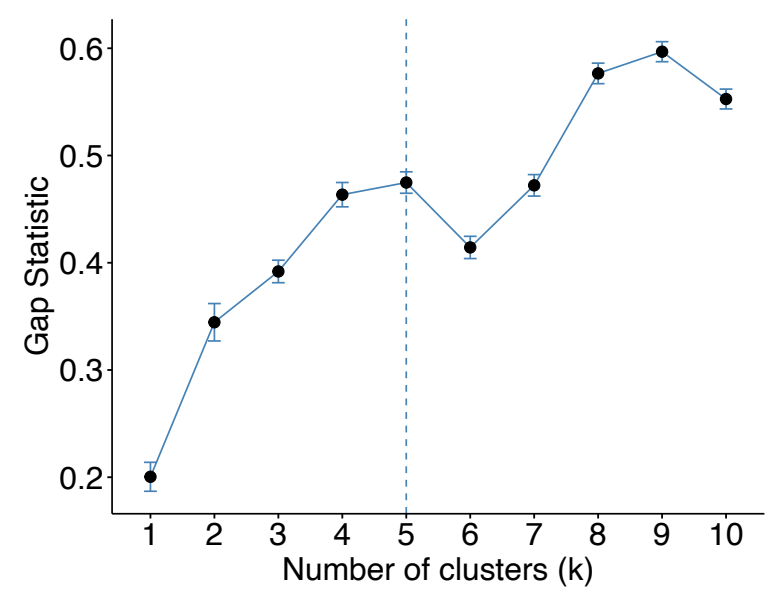

195 Figure 1A: Gap statistic for different numbers of $k$ clusters, ranging from 2 to 10. Larger values

196 indicate greater separation between clusters. An optimal number of clusters based on gap statistic

197 is shown by a dashed vertical line. 


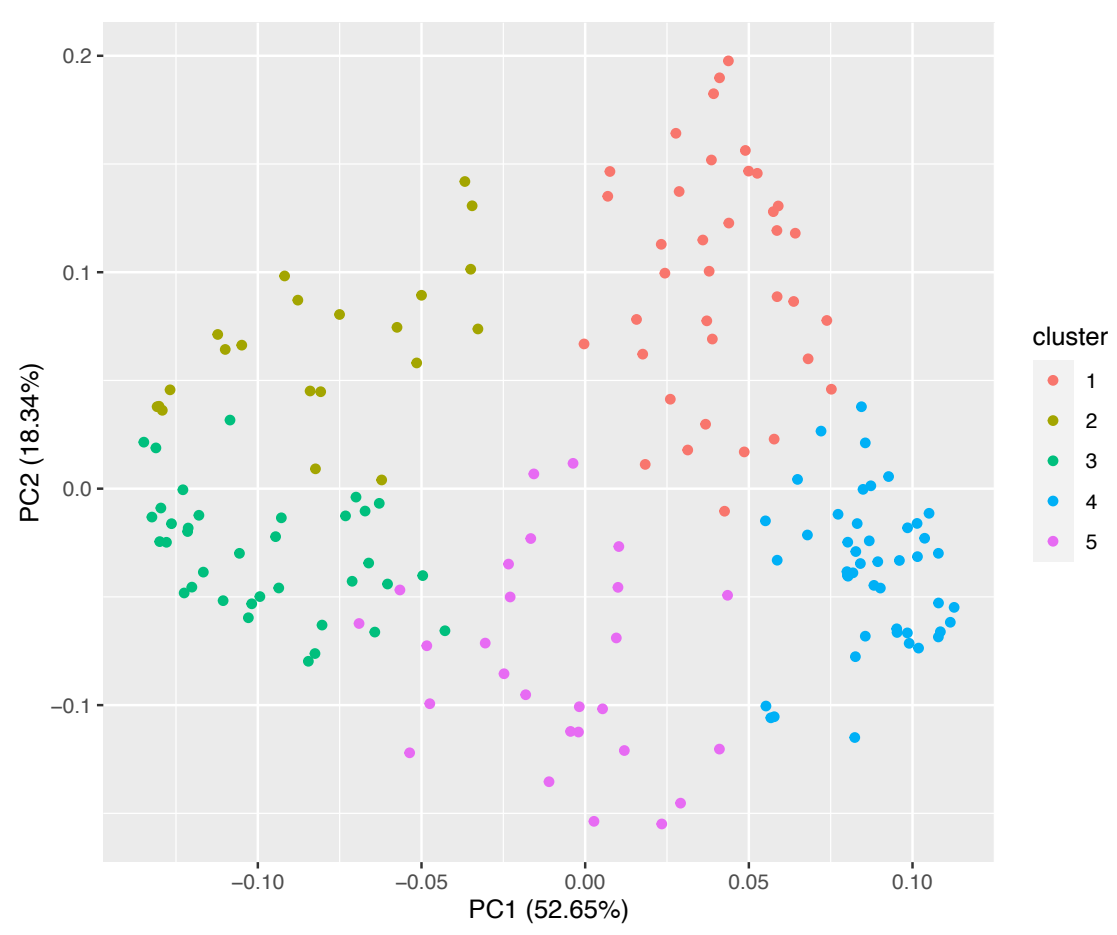

202 Figure 1B: Principal coordinate analysis of 5 clusters, based on Bray-Curtis dissimilarity matrix.

203 The legend showing the color code of each cluster is on the right. Together, the first two

204 principal coordinates capture $>70 \%$ of the variance in these data. Each dot represents one of 167

205 samples in the cross-sectional analysis described in Methods.

207 It is reassuring that choosing 5 clusters also optimizes the ability of communities to explain

208 patient differences in lung function. Figure 1C shows the value of adjusted $\mathrm{r}^{2}$ from linear models

209 of $\mathrm{pFEV}_{1}$, a measure of lung health, as a function of cluster membership. Five clusters explain

210 about $24 \%$ (adjusted $r^{2}=0.24$ ) of patient differences; using six clusters reduces $r^{2}$. In summary,

211 two independent lines of evidence suggest that 5 clusters may be optimal for summarizing these

212 data. 


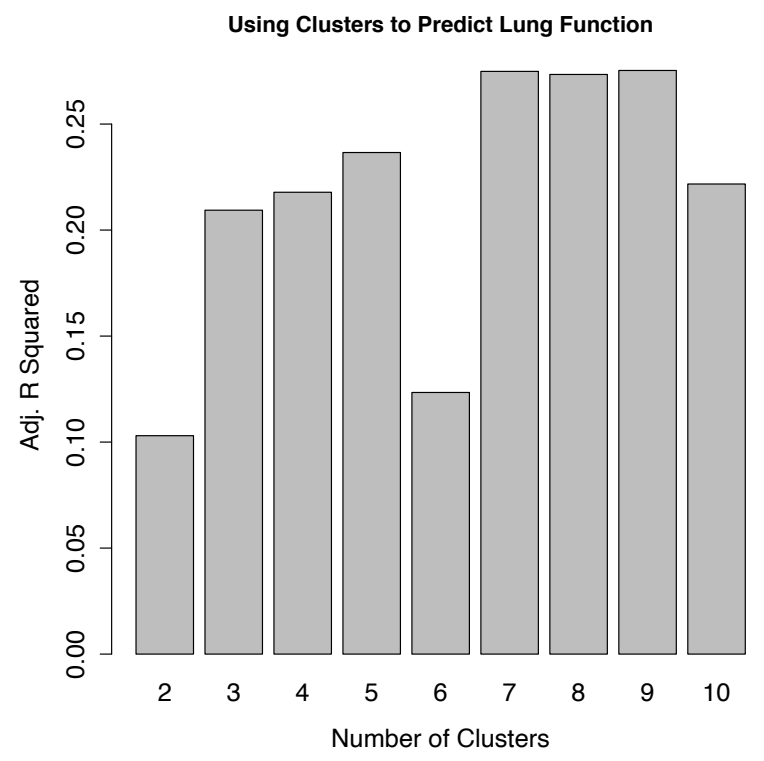

215 Figure 1C: Adjusted r squared from linear models of lung function (ppFEV1) using membership

216 in a given cluster as the independent variable. Models were run for different numbers of $\mathrm{k}$

217 clusters, ranging from 2 to 10.

219 Clusters Membership Predicts Lung Function Better than Pseudomonas Relative Abundance,

220 Age or Community Diversity

222 Despite a reframing of the conversation surrounding the CF airway microbiome away from

223 single pathogens toward ecological descriptions involving species diversity $(14,17-18,48,49)$,

224 the relationship between Pseudomonas and lung function is still frequently cited (14, 23, 49, 50).

225 We used linear models to assess the level of association between lung function and commonly

226 identified explanatory variables such as the relative abundance of Pseudomonas as well as

227 Simpson Diversity and age. As shown in Figure 2, single variables like relative abundance of 
228 Pseudomonas, Simpson diversity and age explain less than $11 \%$ of patient variability in lung

229 function (adjusted $\mathrm{r}^{2}<0.11$ ). In other words, over $89 \%$ of variability in lung function is

230 explained by factors other than Pseudomonas, Simpson diversity or age. The explanatory power

231 of these models improves with increasing complexity, and a combined model that incorporates

232 Simpson diversity, age and the relative abundance of Pseudomonas or other classical CF

233 pathogens in a single model still explains less than $12 \%$ of patient variability in lung function. In

234 contrast, membership in one of the 5 communities identified above explains $24 \%$ of patient

235 variability in lung function. In other words, knowing which cluster a person's airway

236 microbiome belongs to provides a better estimate of their lung function than knowing the relative

237 abundance of Pseudomonas in their airway microbiome (Figure 2).

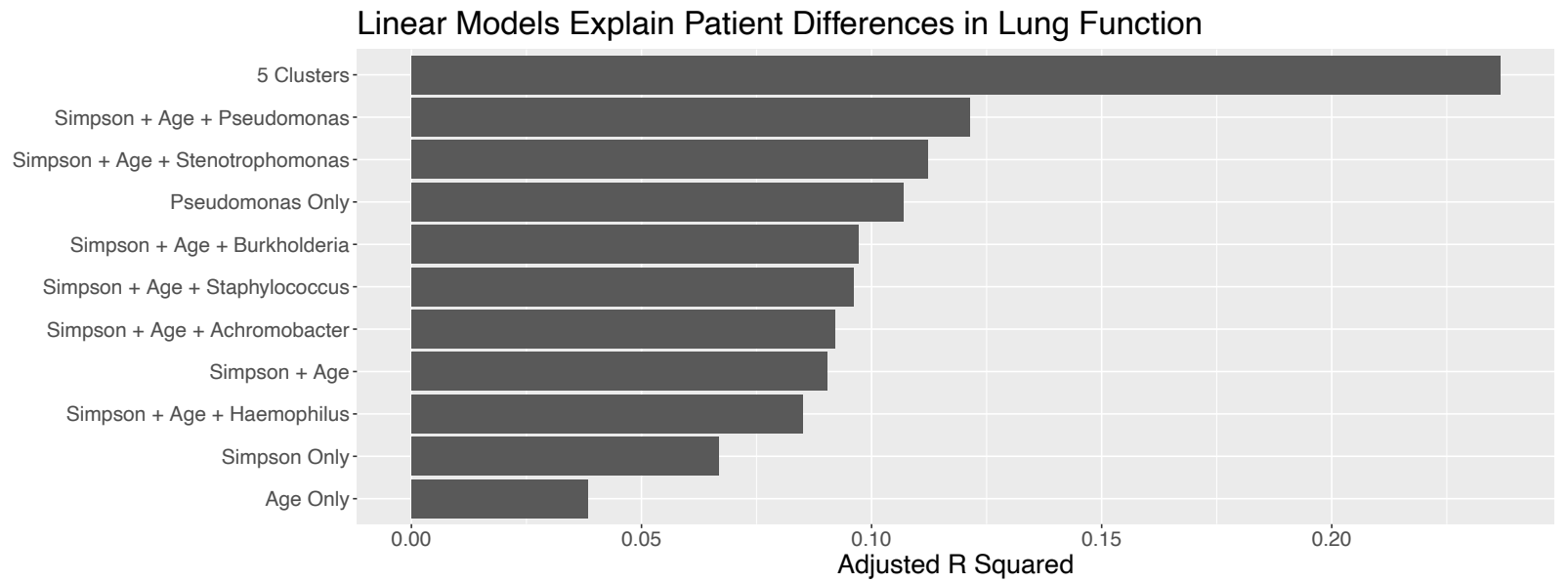

239 Figure 2: The ability of linear models to predict $\mathrm{pFEV}_{1}$, as estimated by adjusted R squared.

240 Individual factors or combinations (denoted by “+”) of covariates shown on y axis: Simpson

241 Diversity only, Age only, Pseudomonas only, the combination of Simpson and Age, or Simpson

242 and Age and the relative abundance of other classic CF pathogens, compared to membership in

243 one of the 5 clusters. 
Top 10 Bacterial Genera Across Clusters

247 We identified the top 10 genera with the highest mean relative abundance across the 167 cross-

248 sectional samples and averaged their relative abundance in each of the 5 clusters, as shown in

249 Figure 3A. Choosing the top 10 genera for visualization still includes the vast majority of the

250 reads (mean 90\%) that mapped to a genus. The first cluster (Str.D), which contained 46 samples

251 was, on average, dominated by Streptococcus (brick red). Clusters 2, 4 and 5 had large amounts

252 of Pseudomonas (olive), but were distinguished by the differences in abundance and/or type of

253 minor genera. Cluster 2 (Pa.D) was dominated by Pseudomonas. While Cluster 4 (Pa.M1) and

254 Cluster 5 (Pa.M2) were similar, they clustered separately, perhaps because Cluster 5 had more

255 Achromobacter and Burkholderia than cluster $4(\mathrm{P}<.001$ asymptotic Wilcoxon-Mann-Whitney

256 test), and Cluster 4 had more Streptococcus $(\mathrm{P}<.001$, asymptotic Wilcoxon-Mann-Whitney

257 test). Cluster 3 (Oth.D) was dominated by a genus other than Streptococcus or Pseudomonas and

258 could be described as having an even mix of genera based on averages.

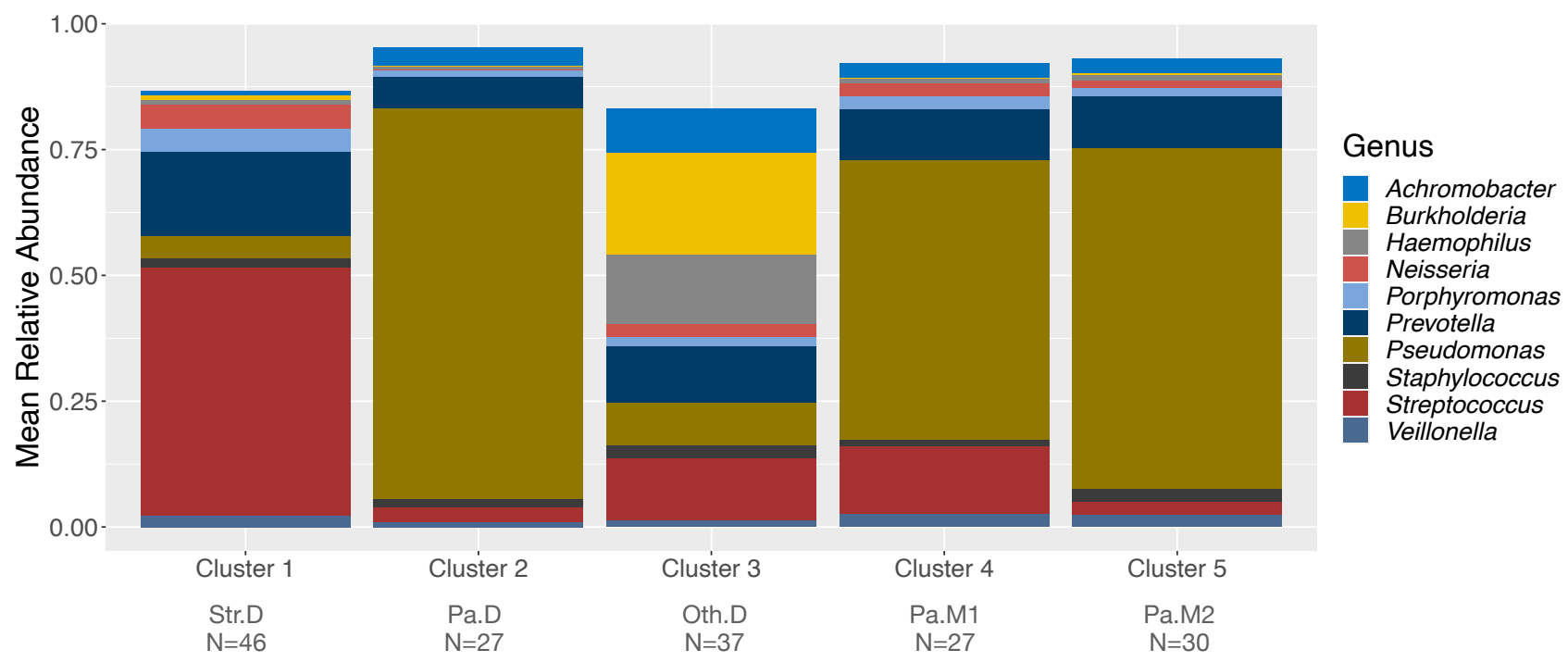


260 Figure 3A: Mean abundances of top 10 genera in each of the 5 clusters. Mnemonic

261 abbreviations: Str.D = Streptococcus dominated, Pa.D = Pseudomonas dominated, Oth.D =

262 Other dominated, Pa.M1 = Pseudomonas mixed community \#1, Pa.M2 = Pseudomonas mixed

263 community \#2. The number of samples that belonged to each cluster appears beneath each

264 cluster mnemonic.

265

266 We then mapped each of these clusters back to the two cross-sectional datasets, as shown in

267 Table 2. The Carmody data set (18) was from as single CF center in the US, and the Cuthbertson

268 data set (17) included subjects from Europe and the US, spanning 13 different CF centers. Some

269 clusters, but not others, were enriched in data from particular studies perhaps as a consequence

270 of biases in sample collection/processing, differences in subject age, and/or systematic

271 differences in patient care. Of note, the two P. aeruginosa mixed communities, Pa.M1 and

272 Pa.M2, largely clustered as a function of the dataset from which they were derived.

273 Interestingly, the Carmody (18) data set had no patients in the P. aeruginosa dominant cluster

274 (Cluster 2, Pa.D), while the Cuthbertson (17) samples, collected over 13 centers had $\sim 1 / 3$ of its

275 sample map to this community cluster. In contrast, for the communities assigned to the Carmody

276 dataset (18), more than half were described as Streptococcus-dominated, while the remaining

277 samples, while containing P. aeruginosa, were more evenly mixed (Pa.M1) or dominated by

278 other pathogens (Oth.D). 


\begin{tabular}{|c|l|r|r|}
\hline Cluster Number & Mnemonic & Carmody & Cuthbertson \\
\hline 1 Str.D & 45 & 1 \\
\hline 2 & Pa.D & 0 & 27 \\
\hline 3 & Oth.D & 19 & 18 \\
\hline 4 & Pa.M1 & 19 & 8 \\
\hline 5 & Pa.M2 & 1 & 29 \\
\hline
\end{tabular}

282 Table 2: Number of subjects in cross sectional data set mapping to various clusters shown in

283 Figure 2, for the Carmody (18) and Cuthbertson (17) data sets.

285 Interestingly, averages do not capture the specifics of a group perfectly, as shown in Figure 3B.

286 Individual samples that mapped to cluster 3 (Oth.D; Other dominated), which when averaged

287 appears to have an even mix of genera, tended to be dominated by individual genera, including

288 Stenotrophomonas which was not among the top 10 most abundant genera across all 167

289 samples. We therefore complemented our analysis of the 10 most abundant genera (on average)

290 with an analysis of the 10 most dominant genera, that is, the top 10 genera achieving the highest

291 relative abundance in any of the 167 samples. 


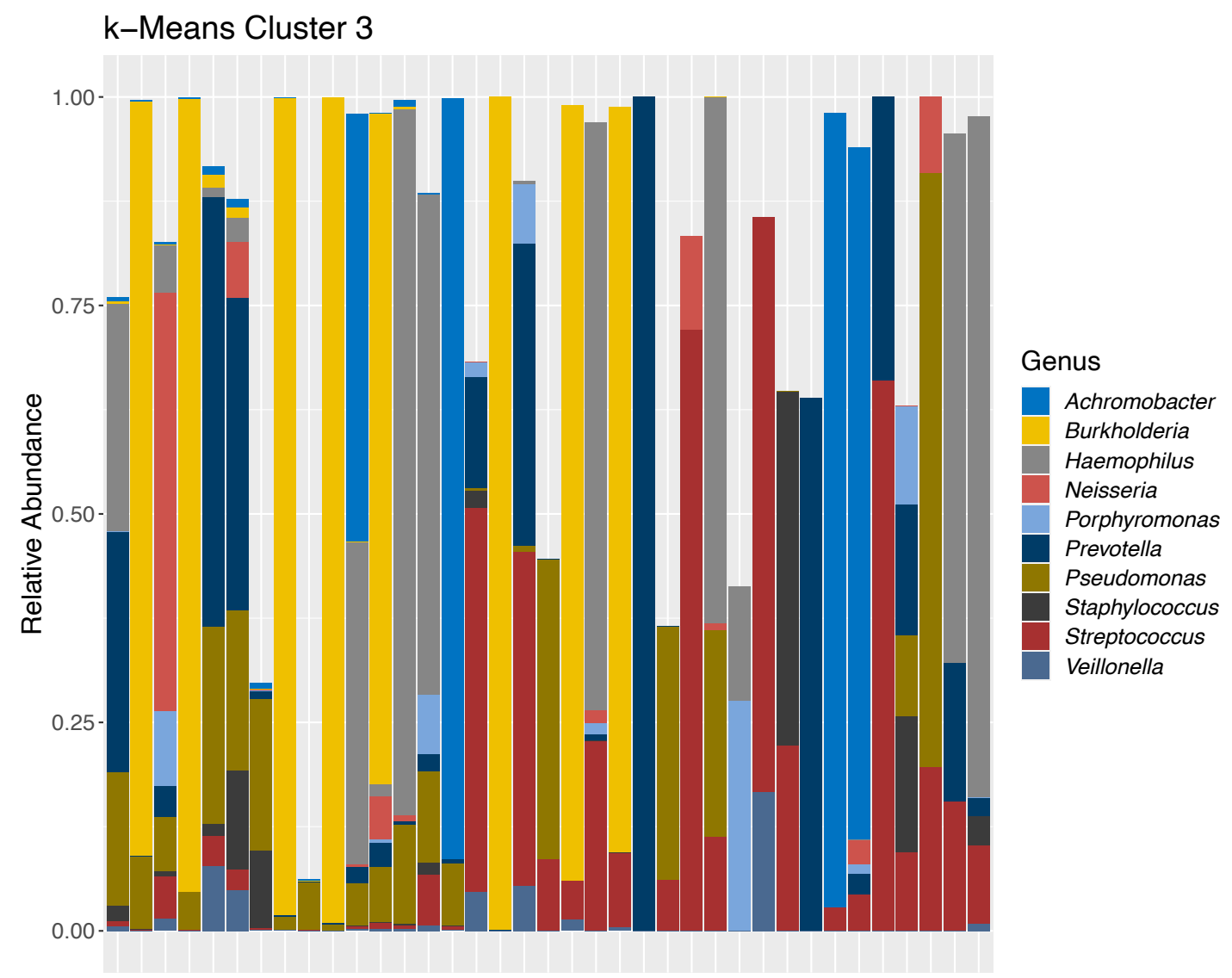

294 Figure 3B: Abundances of top 10 genera relative abundance of cluster 3 (Oth.D) in each of the

29537 samples belonging to this group.

297 Haemophilus, Stenotrophomonas, Burkholderia, Prevotella and Achromobacter achieved high

298 levels of dominance (relative abundance greater than 85\%) in samples in cluster 3, as shown in

299 Figure 3C, but not in other clusters. Streptococcus achieved dominance in cluster 1, but not

300 elsewhere. Pseudomonas achieved high levels in clusters 2, 4 and 5. 


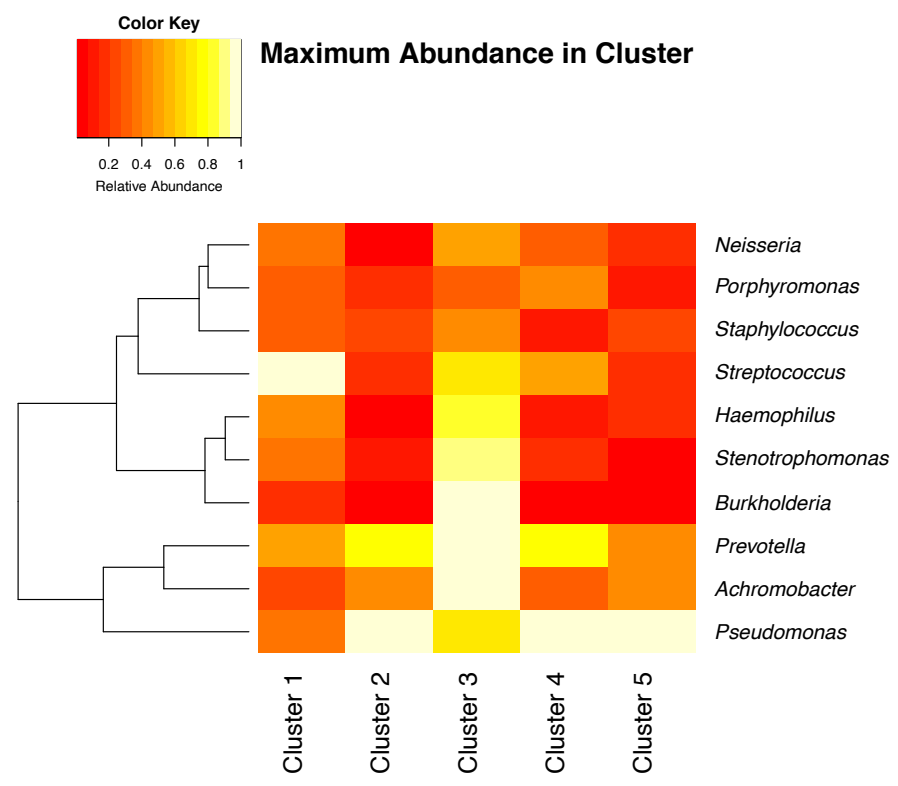

302

303 Figure 3C: Maximum abundance of 10 genera achieving the highest relative abundance in any of

304 the 167 samples, as a function of cluster.

Clusters Dominated by Streptococcus and Pseudomonas Differ in Lung Function and Age

308 It has previously been observed that species from the Streptococcus genus are part of the core CF

309 airway microbiome $(16,31,50)$, that the prevalence of Streptococcus spp. is sometimes

310 associated with less severe lung function loss $(12,14,31,51)$, but that some genera of

311 Streptococcus, including anginosus group streptococci (AGS; also known as the milleri group

312 streptococci) may facilitate exacerbation (25-27). Our cross-sectional analysis highlights the

313 positive aspect of patients carrying the community dominated by Streptococcus; subjects whose

314 airway microbiomes were characterized as Streptococcus-dominated tended to have better lung

315 function, as shown in Figure 4A, and be younger, as shown in Figure 4B. 


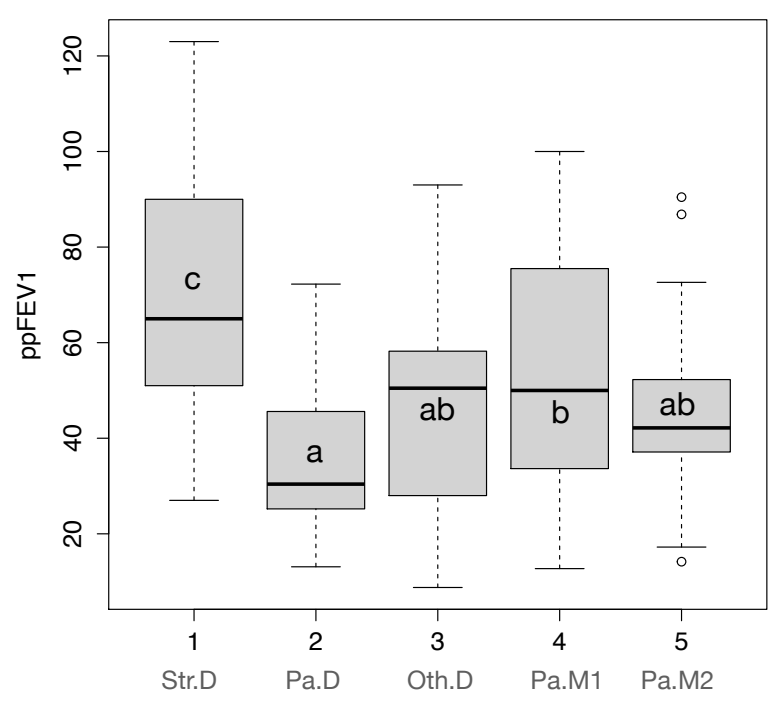

318 Figure 4A: Association of communities with lung function. Subject-Lung Function profiles of 5

319 distinct communities. Box and whisker plot comparing ppFEV1 between Streptococcus-

320 dominated (Str.D), Pseudomonas-dominated (Pa.D), communities dominated by other genera

321 (Oth.D), Pseudomonas mixed community \#1 (Pa.M1), and Pseudomonas mixed community \#2

322 (Pa.M2), as shown in Figure 3A. Communities sharing a common letter are not significantly

323 different; those with no letter in common differ significantly (Tukey Honest significant

324 difference $\mathrm{P}<.05)$. For example, subjects with Str.D communities had higher $p p F E V_{1}$ than those 325 with any other community type. 


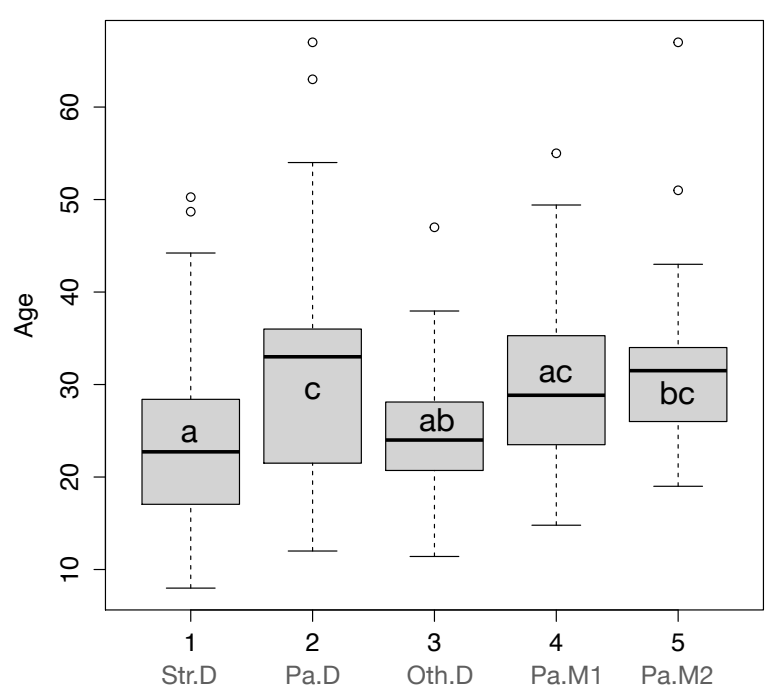

328 Figure 4B: Association of communities with age. Subject-age profiles of 5 distinct communities.

329 Box and whisker plot comparing age between Streptococcus-dominated (Str.D), Pseudomonas-

330 dominated (Pa.D), communities dominated by other genera (Oth.D), Pseudomonas mixed

331 community \#1 (Pa.M1), and Pseudomonas mixed community \#2 (Pa.M2), as shown in Figure

332 3A. Communities sharing a common letter are not significantly different; those with no letter in

333 common differ significantly (Tukey Honest significant difference $\mathrm{P}<.05$ ). For example, subjects

334 with Str.D communities were younger than those with Pa.D communities or Pa.M2 communities

335 but did not differ significantly in age from subjects with Oth.D or Pa.M1 communities.

Communities Observed in Subjects with Mild versus Moderate/Severe Disease are Similar

339 Findings in the cross-sectional data (Figure 4A, B) are consistent with previous reports showing

340 that communities dominated by Pseudomonas tend to be associated with older subjects and

341 reduced lung function $(36,39,44)$. Given that young, healthier pwCF tend to have sputum

342 communities dominated by Streptococcus led to the hypothesis that people with such 
343 Streptococcus-dominated communities ultimately transition to communities dominated by

344 Pseudomonas as they age. To probe this idea, we used a longitudinal data set to assess how

345 communities changed in the 24 subjects detailed in Table 1 , for whom there are 10 or more

346 longitudinal samples collected for times periods ranging from $\sim 6-10$ years (average of $\sim 8$ years).

348 For this analysis we used supervised machine learning to track community type changes in

349 individuals with CF through time. Briefly, we used random forests (52) to identify features that

350 reliably classify a sample as belonging to one of the five previously identified communities.

351 This classifier enabled us to identify the community type of 346 16S rRNA gene amplicon

352 datasets from 24 subjects that were observed across many years (18). This longitudinal data set

353 included 16S rRNA gene amplicon dataset measurements made in different clinical states

354 (baseline, exacerbation, treatment and recovery) and includes clinical metadata such as whether a

355 subject had been diagnosed as having mild or more severe disease. This approach mapped the

356346 16S rRNA gene amplicon datasets to the four communities shown in Figure 3, specifically,

357 Str.D., Pa.D, Pa.M1 and Oth.D. No samples in the Carmody (18) longitudinal data mapped to

358 Pa.M2, consistent with the description of Pa.M2 cluster being specific Cuthbertson (17) dataset

359 (see Table 2).

361 Roughly two or three community types were required to describe any given subject over time,

362 recapitulating previous reports that the CF airway microbiome is fairly stable over time $(15,18$,

$36319,38,45,46)$, but may shift in structure around the time of exacerbation or in response to

364 antibiotic therapy $(23,45)$. We did not observe large differences in community types between

365 subjects with mild disease compared to moderate/severe disease either as a function of subject 
366 (Figure 5A) or disease state (Figure 5B). For example, subject 117 was observed 15 times to

367 show a Streptococcus dominated community (Str.D) and 5 times to show the Pseudomonas

368 mixed community number 1 (Pa.M1).

370 We do note some associations. For example, domination by a pathogen other than Pseudomonas

371 (Oth.D) was associated with decreased probability of being observed in the baseline state (p-

372 value $=0.004$, odds ratio 0.43, Fisher's exact test). Furthermore, despite similarities, subjects

373 with mild disease did differ from those with moderate/severe disease in specific ways. Subjects

374 with mild disease were more likely to be observed having a community classified as Pa.M1 (p-

375 value $=0.02$, odds ratio $=1.69$, Fisher's exact test $)$ and more likely to be observed in the baseline

376 state $(\mathrm{p}$-value $=3.1 \mathrm{e}-06$, odds ratio $=2.8$, Fisher's exact test $)$ than people with moderate $/$ severe

377 disease.

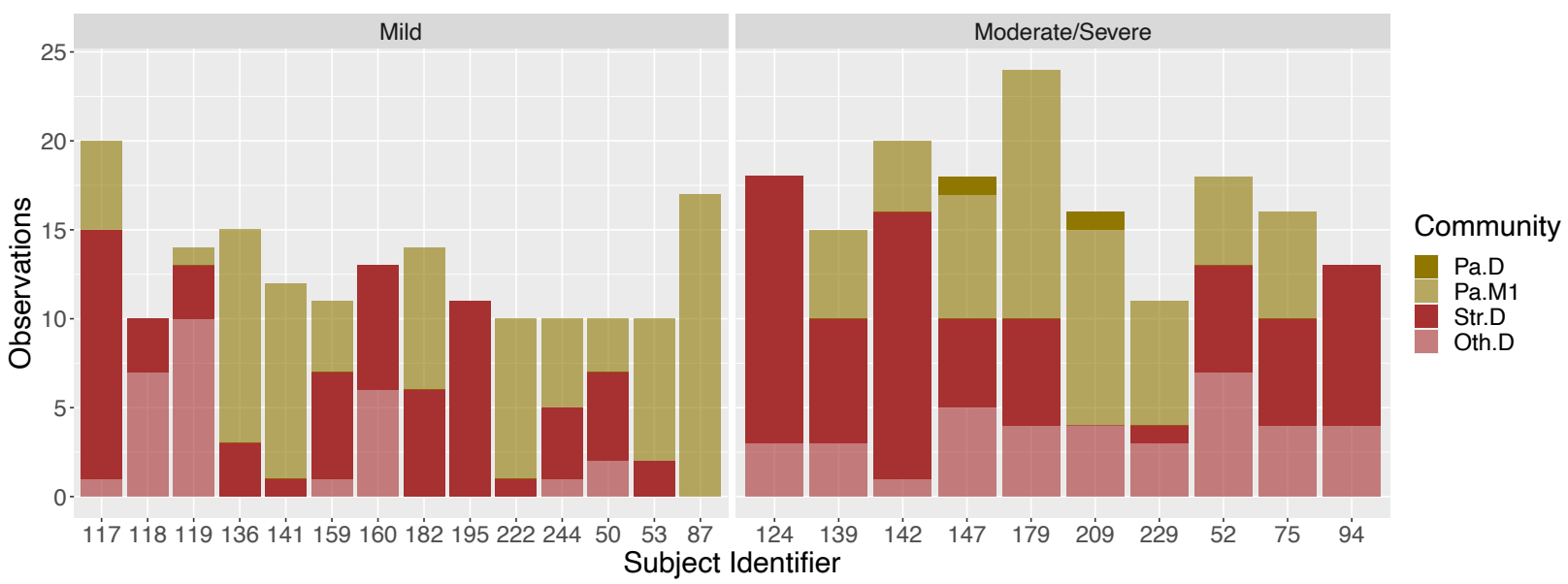

380 Figure 5A: Frequency of observing various community types in subjects designated as having

381 mild or moderate/severe disease. Subjects with mild disease $(\mathrm{N}=14$, left) are compared to

382 subjects with moderate/severe disease $(\mathrm{N}=10$, right). "Subject identifier" corresponds to "isolate" 
383 in Table 1, a field provided in the Carmody (18) data set. Community types identified in these

384 longitudinal samples were deemed similar to those in Figure 3A by random forest classifier.

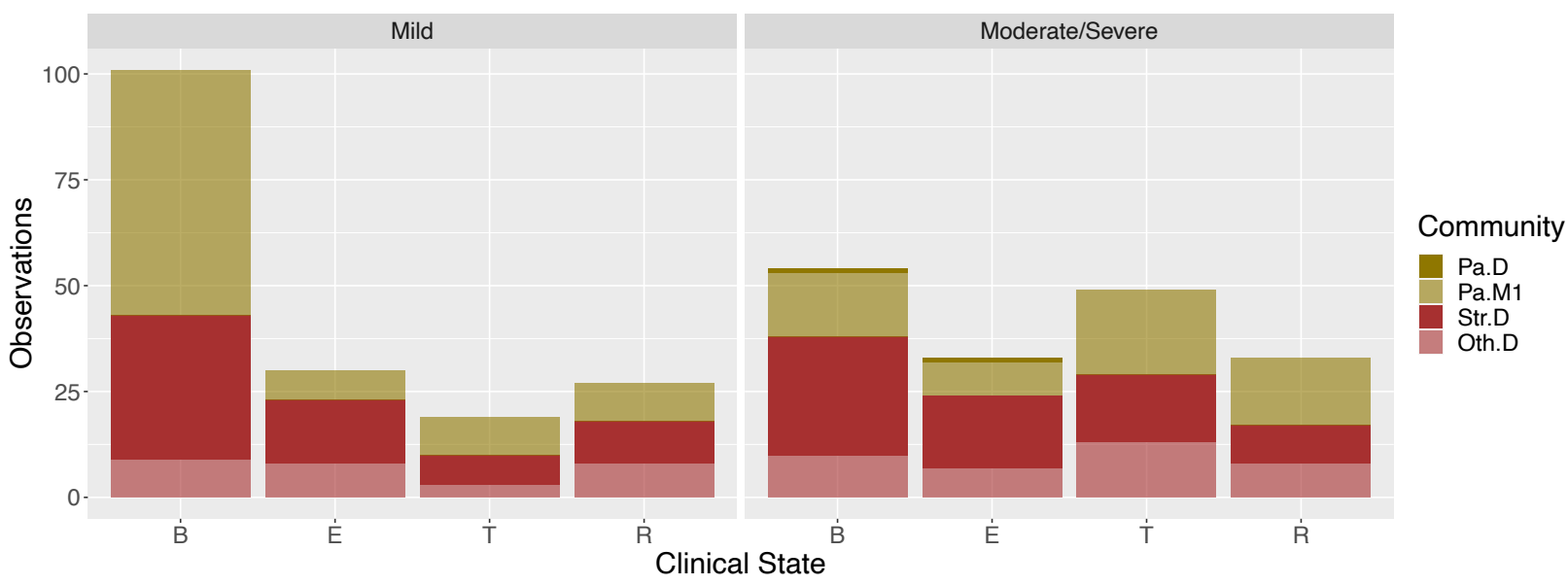

Figure 5B: Frequency of observing various clinical states for the 14 subjects with mild disease aggressiveness (left) and 10 subjects with moderate/severe disease (right) as shown in Table 1.

391 Clinical states are defined as $(\mathrm{B}=$ baseline, $\mathrm{E}=$ exacerbation, $\mathrm{T}=$ treatment, $\mathrm{R}=$ Recovery $)$.

392 Community types identified in these longitudinal samples were deemed similar to those in Figure 393 3A by random forest classifier.

396 Interestingly, we note that people with mild disease have bacterial communities that are more

397 stable over time based on being observed in a specific community category (Figure 5). We tested 398 this association using a continuous variable by calculating Bray-Curtis distances for all pairwise 399 comparison of samples taken from any given subject over time. As shown in Figure 6A, 
401 communities from subjects with moderate/severe disease, suggesting that variation in community

402 composition is associated with worse disease outcomes.

403

404

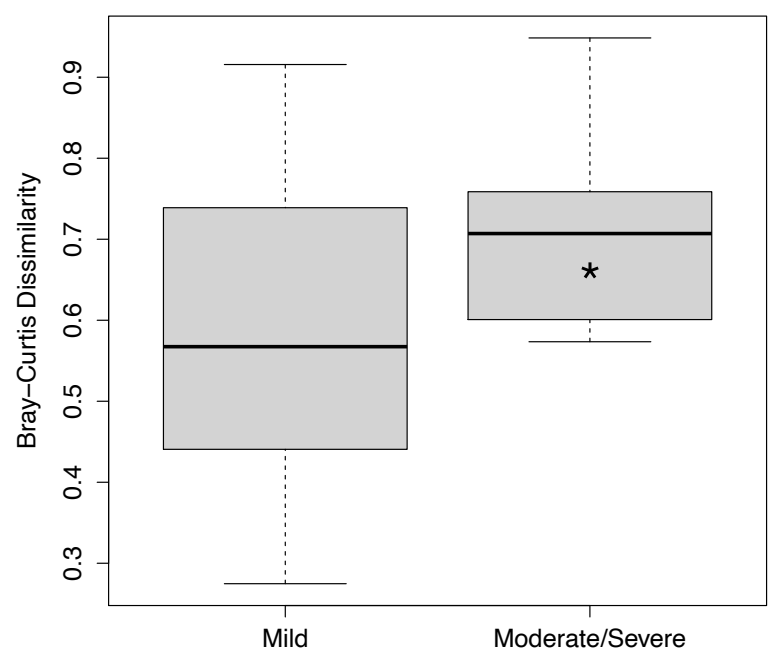

Figure 6A: Median within-subject pairwise distances (Bray-Curtis dissimilarity) for $\mathrm{N}=14$ similar to each other ( “*” signifies $\mathrm{P}<.05$, Wilcoxon rank sum exact test).

412 As a second approach to assess the association between community stability and clinical

413 outcome, a Markov chain analysis was performed to track subjects and their associated

414 community types across time. Markov models simplify dynamic systems by representing them as 415 a set of finite states that are connected to each other enabling transitions between the states. With 416 enough data, the geometry of these systems (i.e., states that are connected to each other, enabling 
417 a transition) can be determined. In addition, the probability of transitioning between any two

418 connected states can be estimated. Markov modeling of this system suggests that this self-

419 similarity arises at least partly because subjects with mild disease are repeatedly observed with a

420 Pa.M1 community type (Figure 6B). Specifically, given that a subject was characterized as

421 having mild disease and was last observed with community type Pa.M1, they had a 73\%

422 probability of being observed in Pa.M1 again. In contrast, the geometry associated with

423 moderate/severe disease was more complex, and subjects were less likely to remain in the Pa.M1

424 state $(60 \%)$ and also found more often in the Pa.D community (Figure 6C). Overall, repeated

425 observation of Pa.M1 was significantly more likely in subjects with mild disease compared to

426 moderate/severe disease (red arrow in 6B: “*” indicates $\mathrm{P}=.03$, Fisher's exact test, odds ratio

427 1.78). Together, these data indicate that patients with stable communities tend to have better

428 airway function. 


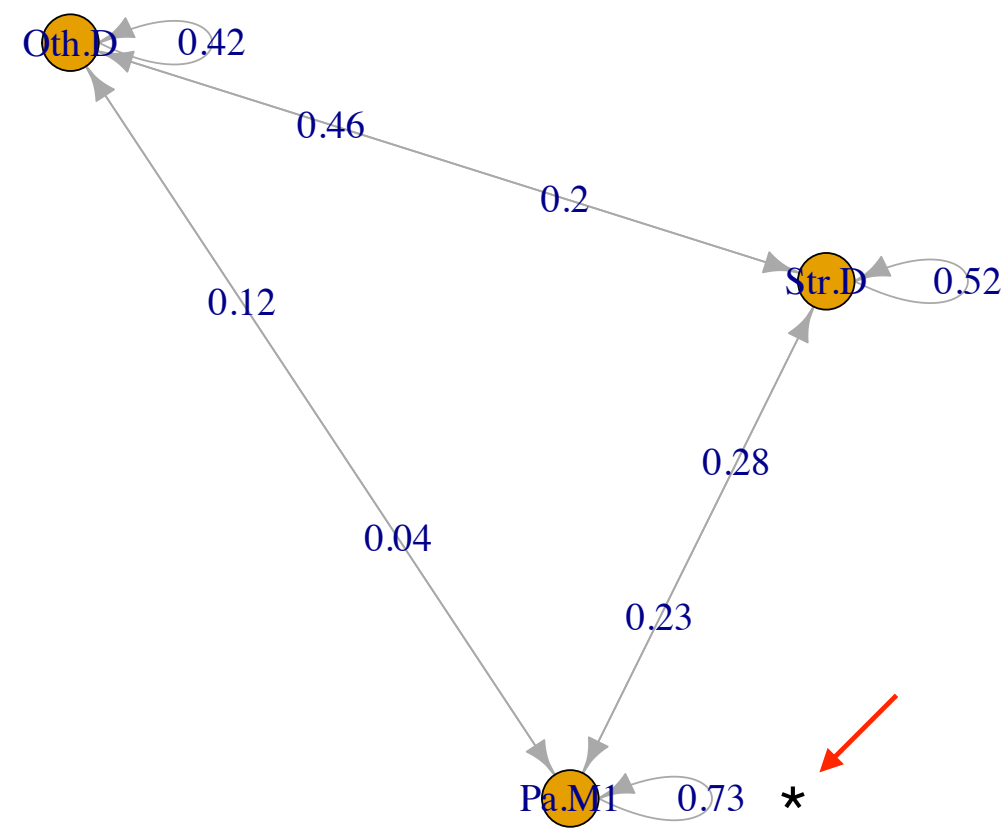

431 Figure 6B: Markov chain diagram for community transitions in subjects with mild disease (see

432 Table 1). Each node in the diagram (orange circles) represents the state of being observed with a

433 specific bacterial community. Edges leading from each node represent possible transitions, 
434 including the possibility of observing the same community again (loop). Numbers on arrows are 435 estimates of the probability of taking a specific path.

436

437

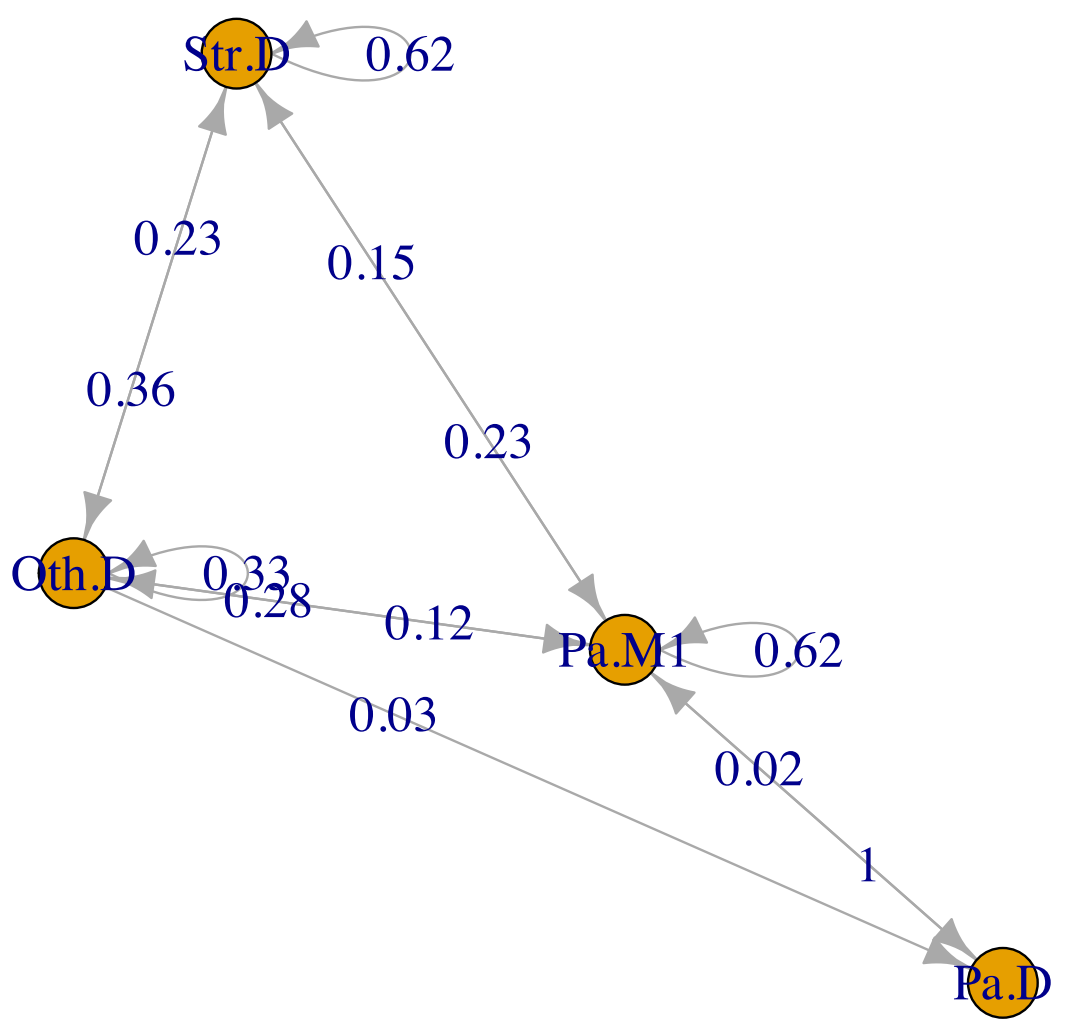

439 Figure 6C: Markov chain diagram for community transitions in subjects with moderate/severe

440 disease (see Table 1). Each node in the diagram (orange circles) represents the state of being 441 observed with a specific bacterial community. Edges leading from each node represent possible 
442 transitions, including the possibility of observing the same community again (loop). Numbers on

443 arrows are estimates of the probability of taking a specific path.

\section{DISCUSSION}

447 We present two major findings in this report. First, the previously reported climax-attack model

448 postulates that an attack community composed of genera like Streptococcus, Veillonella and

449 Porphyromonas, perturbs a climax community dominated by Pseudomonas and Staphylococcus

450 (28), resulting in a metabolic shift toward fermentation and decreasing $\mathrm{pH}$. These conditions are

451 more favorable to fermentative bacteria like Prevotella, Veillonella, Streptococcus, Rothia and

452 Granulicatella (28). Our observation that mild disease is associated with community stability,

453 and that stability is associated with a Pseudomonas-dominated community are therefore

454 consistent with the climax-attack model of CF.

456 Second, we have shown that a relatively small number of CF microbiome types explain patient

457 differences in lung function, and that they explain these differences much better than single

458 variables like the relative abundance of Pseudomonas, age or Simpson diversity. This finding is

459 important because developing interventions to treat the community as the pathogenic unit will

460 require a reasonable number of experimentally tractable model communities. Without such

461 models, we would be faced by a dizzying array of patient differences. Fortunately, the airway

462 community in a pwCF over multiple samplings generally looks more like "self" than any other

463 patient when using relative abundance of bacteria as a metric of what defines a community

464 increasing the likelihood of identifying an in vitro model that might help design more effective 
treatment regimens for a pwCF that has a similar community composition. Our findings raise the question of what combinations of abundant microbes (Pseudomonas, Streptococcus,

467 Staphylococcus) and less abundant community members (i.e., anaerobic, fermentative organisms) really matter? Does it matter if a patient has $90 \%$ Pseudomonas versus $80 \%$ or $70 \%$ ? Intriguingly, Pseudomonas, often listed as the quintessential CF pathogen, is highly abundant in long lived people with CF, an aspect of a "survivor phenotype" (53). Alternatively, does it matter

471 if the dominant microbe in a community is Streptococcus rather than Pseudomonas, or if the

472 minor players are Prevotella versus Veillonella versus Gemella? Although unsupervised 473 machine learning cannot answer these questions with precision, we have demonstrated that as

474 few as five communities may represent a useful starting point as pwCF with a particular community type experience significantly similar lung function as measured by $p \mathrm{pFEV} \mathrm{V}_{1}$

There are several critical factors and caveats to consider in light of the interpretations we make sectional data set used here, one should avoid construing "five" as the number of distinct populations in the CF community. Children younger than eight were not included in this study,

481 and it is possible that broad sampling of young pwCF would have enabled us to identify

482 additional clusters. In the same vein, although cluster 3 (Oth.D) contains subjects that were 483 dominated by genera other than Pseudomonas, it is understood that broader sampling of this 484 group would create additional clusters for each genus in cluster 3. Nonetheless, some of the 485 findings here mirror the conclusions from previous studies with smaller data sets $(12,15,44)$.

486 Second, this study includes both cross-sectional and longitudinal observations of airway 487 microbiomes and associated clinical parameters, enabling us to identify associations between 
them. However, this type of study cannot prove causation. Indeed, our interpretation of the data here should rightly be viewed as hypotheses to be tested either via additional clinical studies or

490 in the laboratory. Third, and related to the previous point, the most useful aspect of this work is 491 that it does set a framework for hypothesis testing, for example, can we build the communities

492 we observe here in vitro and assess their function (i.e., are some clusters of microbes more/less

493 cytotoxic or more/less recalcitrant to antibiotics)? Alternatively, are similar communities

494 associated with positive/negative health outcomes in other cohorts of pwCF or in other disease

495 settings? For example, a recent report by Frey et. al. (29) concludes that airway diversity is a

496 biomarker of lung disease severity that links dysbiosis to lung function decline in pwCF. They

497 observed a negative correlation between inflammatory cytokine secretion and airway community

498 diversity, suggesting that more diverse communities are for some reason more salubrious than

499 less diverse communities (a common but unexplained finding across many microbiome studies).

500 Using a slightly different unsupervised approach to identify CF airway communities (i.e.,

501 hierarchical clustering of Unifrac distances), these investigators found that high diversity maps to

502 an oropharyngeal-like community typically found in younger people. The authors carefully avoid

503 making the claim that bacterial diversity reduces inflammation, although others have reported

504 this association (50) or found a positive association between higher lung function and increased

505 bacterial diversity $(14,17)$. The diverse, oropharyngeal-like community identified by Frey is

506 characterized by anaerobes like Prevotella and Veillonella and aerobic commensals including

507 Neisseria and Streptococci, making it very similar to the Streptococcus dominated community

508 (Str.SD) identified in this report (Figure 3); our Str.D community was also associated with higher

509 lung function (Figure 4A) and relative youth (Figure 4B) in pwCF. Thus, orthogonal approaches 
510 appear to converge on similar conclusions as to community composition associated with less

511 severe health outcomes.

513 The findings here and reported by Frey et. al. (29) and others $(14,50,51)$ raise the question of

514 whether remodeling CF airway communities to make them more diverse and more similar to the

515 oropharyngeal communities found in younger people with higher lung function, if possible,

516 might improve outcomes in $\mathrm{CF}$. There are several reasons to question the wisdom of attempting

517 to turn back the hands of time in older subjects and enhance the abundance of oropharyngeal

518 flora in their airways. First, as described above, it is possible that the introduction of diversity

519 into an established community (for example, one dominated by Pseudomonas) would destabilize

520 the community and lead to enhanced inflammation, as suggested by the climax-attack model of

521 CF (54). Second, as demonstrated by Muhlebach (55), inflammation increases when pediatric

522 pwCF are first colonized by oropharyngeal flora; although this finding should not be surprising,

523 it is worth pointing out that the best airway community is probably no community at all. Third,

524 even in adults, increased diversity is not uniformly benign. Studies by Raghuvanshi et al. (24)

525 show a linear increase in the microbiome alpha-diversity and in the log ratio of anaerobes to

526 pathogens two weeks before a pulmonary exacerbation, confirming similar observations by

527 Carmody et al. (18) showing that bacterial community diversity and the relative abundance of

528 anaerobes increased during exacerbations, i.e., before antibiotic treatment. Others have shown

529 that treating adults with antibiotics primarily affects taxa other than classic CF pathogens (56,

530 57), and that antibiotics reduce the abundance of Streptococcus, Prevotella and Veillonella, but

531 not Pseudomonas, the ostensible target of treatment. Collectively then, the results cited support 
532 the somewhat surprising conclusion that oropharyngeal flora are associated with worse airway

533 disease, and that treatments work because they reduce the abundance of oropharyngeal genera.

535 Finally, as mentioned above, we present just one approach for analyzing the extant microbial

536 community data associated with CF airway infections, but an approach that has both statistical

537 support and practical utility. That is, it is likely that only controlled experiments using model

538 communities in laboratory or animals can unravel the mechanistic role played by oropharyngeal-

539 like flora in an established adult microbiome $(14,25,50,58)$ and to understand the functional

540 consequences of community composition. That is, we have identified 5 communities comprised

541 of 10 genera, which presents an experimentally tractable numbers of communities and microbes.

542 As another example, Crabbe et al. (59) recently reported using a nine member community for in

543 vitro studies. Going forward, this and other studies can help inform the nature of laboratory

544 model communities used to probe the hypotheses we and others have developed by analyzing

545 clinical datasets.

547 Acknowledgements: Support for these studies was provided by the Cystic Fibrosis Foundation

548 (CFF STANTO19R0 and STANTO19GO) and NIH (R01HL151385, R37 AI083256-06, and

549 P30 DK117469 for facilitating analysis of publicly available datasets and for advice to

550 Dartmouth colleagues). We would like to thank Dr. John LiPuma for access to his team's data

551 and many helpful insights about this project. 
Table 1. Characteristics of 24 subjects with at least 10 longitudinal samples.

\begin{tabular}{|c|c|c|c|c|c|c|c|}
\hline isolate & Aggressiveness & $\mathbf{N}$ & $\begin{array}{l}\text { Period } \\
\text { (yr) }\end{array}$ & $\begin{array}{l}\text { Median } \\
\text { Age }\end{array}$ & $\begin{array}{l}\text { Median } \\
\text { FEV1 }\end{array}$ & Clinical States & FEV1/yr \\
\hline 75 & Moderate/Severe & 16 & 8.99 & 14.9 & 32.5 & R,E, T, T,E,R,B,B,R, T,E,B,B,R,B,R & -2.23 \\
\hline 139 & Moderate/Severe & 15 & 6.64 & 15.1 & 34 & $\mathrm{~B}, \mathrm{~B}, \mathrm{~B}, \mathrm{~T}, \mathrm{R}, \mathrm{T}, \mathrm{B}, \mathrm{B}, \mathrm{B}, \mathrm{B}, \mathrm{R}, \mathrm{B}, \mathrm{T}, \mathrm{T}, \mathrm{R}$ & -5.17 \\
\hline 94 & Moderate/Severe & 13 & 9.16 & 17.2 & 39 & $\mathrm{~T}, \mathrm{~T}, \mathrm{E}, \mathrm{E}, \mathrm{T}, \mathrm{B}, \mathrm{E}, \mathrm{B}, \mathrm{B}, \mathrm{B}, \mathrm{B}, \mathrm{R}, \mathrm{R}$ & 1.56 \\
\hline 229 & Moderate/Severe & 11 & 7.27 & 19.2 & 34 & $\mathrm{R}, \mathrm{R}, \mathrm{R}, \mathrm{B}, \mathrm{B}, \mathrm{T}, \mathrm{R}, \mathrm{B}, \mathrm{T}, \mathrm{B}, \mathrm{B}$ & -4.50 \\
\hline 52 & Moderate/Severe & 18 & 9.74 & 23.0 & 43.5 & $\begin{array}{l}T, E, R, R, T, R, R, B, R, R, B, E, E, B, B, B, E, \\
T, R, R\end{array}$ & -1.84 \\
\hline 179 & Moderate/Severe & 24 & 8.66 & 23.8 & 41 & $\begin{array}{l}\mathrm{B}, \mathrm{E}, \mathrm{T}, \mathrm{T}, \mathrm{B}, \mathrm{E}, \mathrm{T}, \mathrm{R}, \mathrm{B}, \mathrm{B}, \mathrm{E}, \mathrm{B}, \mathrm{R}, \mathrm{R}, \mathrm{E}, \mathrm{R}, \mathrm{T}, \\
\mathrm{B}, \mathrm{T}, \mathrm{E}, \mathrm{R}, \mathrm{B}, \mathrm{E}, \mathrm{E}\end{array}$ & -3.08 \\
\hline 159 & Mild & 11 & 7.97 & 24.3 & 82 & $\mathrm{~B}, \mathrm{~B}, \mathrm{~B}, \mathrm{E}, \mathrm{B}, \mathrm{B}, \mathrm{B}, \mathrm{B}, \mathrm{B}, \mathrm{B}, \mathrm{R}$ & -1.20 \\
\hline 87 & Mild & 17 & 7.54 & 25.0 & 82 & $\mathrm{~T}, \mathrm{~T}, \mathrm{R}, \mathrm{B}, \mathrm{E}, \mathrm{B}, \mathrm{B}, \mathrm{B}, \mathrm{B}, \mathrm{B}, \mathrm{R}, \mathrm{T}, \mathrm{R}, \mathrm{B}, \mathrm{R}, \mathrm{B}, \mathrm{B}$ & 1.84 \\
\hline 160 & Mild & 13 & 8.01 & 25.2 & 73 & $\mathrm{~B}, \mathrm{~T}, \mathrm{~B}, \mathrm{~B}, \mathrm{R}, \mathrm{B}, \mathrm{R}, \mathrm{B}, \mathrm{R}, \mathrm{B}, \mathrm{T}, \mathrm{E}, \mathrm{B}$ & 0.79 \\
\hline 142 & Moderate/Severe & 20 & 10.14 & 25.4 & 67 & $\begin{array}{l}\mathrm{B}, \mathrm{T}, \mathrm{T}, \mathrm{T}, \mathrm{T}, \mathrm{E}, \mathrm{B}, \mathrm{R}, \mathrm{T}, \mathrm{T}, \mathrm{E}, \mathrm{E}, \mathrm{R}, \mathrm{B}, \mathrm{T}, \mathrm{E}, \mathrm{B}, \\
\mathrm{R}, \mathrm{T}, \mathrm{E}\end{array}$ & -1.16 \\
\hline 141 & Mild & 12 & 8.91 & 26.3 & 85.5 & $\mathrm{R}, \mathrm{E}, \mathrm{R}, \mathrm{B}, \mathrm{B}, \mathrm{B}, \mathrm{R}, \mathrm{T}, \mathrm{B}, \mathrm{R}, \mathrm{B}, \mathrm{T}$ & -0.20 \\
\hline 124 & Moderate/Severe & 18 & 10.24 & 26.3 & 54.5 & $\begin{array}{l}\mathrm{B}, \mathrm{B}, \mathrm{T}, \mathrm{B}, \mathrm{T}, \mathrm{B}, \mathrm{E}, \mathrm{T}, \mathrm{B}, \mathrm{E}, \mathrm{B}, \mathrm{E}, \mathrm{B}, \mathrm{E}, \mathrm{T}, \mathrm{B}, \mathrm{E}, \\
\mathrm{B}, \mathrm{B}\end{array}$ & -1.00 \\
\hline 147 & Moderate/Severe & 18 & 8.17 & 27.2 & 36.5 & $\mathrm{~B}, \mathrm{R}, \mathrm{E}, \mathrm{E}, \mathrm{B}, \mathrm{B}, \mathrm{B}, \mathrm{B}, \mathrm{B}, \mathrm{T}, \mathrm{R}, \mathrm{T}, \mathrm{T}, \mathrm{T}, \mathrm{B}, \mathrm{B}, \mathrm{R}$, & -3.73 \\
\hline 209 & Moderate/Severe & 16 & 7.87 & 28.0 & 37.5 & T,B,T,B,E,T,R,E,R,R,R,T,R,R,B,R & -6.97 \\
\hline 53 & Mild & 10 & 5.35 & 28.6 & 69.5 & $\mathrm{E}, \mathrm{R}, \mathrm{T}, \mathrm{E}, \mathrm{B}, \mathrm{E}, \mathrm{B}, \mathrm{E}, \mathrm{B}, \mathrm{NA}, \mathrm{NA}$ & 1.55 \\
\hline 182 & Mild & 14 & 5.69 & 29.0 & 83.5 & T,B,R,E,E,B,B,B,B,B,B,E,E,E & -2.28 \\
\hline 118 & Mild & 10 & 7.33 & 30.3 & 58.5 & $\mathrm{E}, \mathrm{T}, \mathrm{B}, \mathrm{R}, \mathrm{B}, \mathrm{B}, \mathrm{B}, \mathrm{T}, \mathrm{R}, \mathrm{E}$ & -1.33 \\
\hline 244 & Mild & 10 & 6.42 & 30.8 & 74.5 & $\mathrm{E}, \mathrm{R}, \mathrm{B}, \mathrm{B}, \mathrm{R}, \mathrm{B}, \mathrm{B}, \mathrm{B}, \mathrm{E}, \mathrm{B}$ & -2.23 \\
\hline 222 & Mild & 10 & 7.47 & 33.5 & 97 & $\mathrm{~B}, \mathrm{R}, \mathrm{B}, \mathrm{T}, \mathrm{B}, \mathrm{T}, \mathrm{B}, \mathrm{B}, \mathrm{B}, \mathrm{NA}$ & -0.21 \\
\hline 136 & Mild & 15 & 7.6 & 36.8 & 57 & $B, R, B, E, B, B, T, R, B, R, E, E, B, T, B$ & -2.99 \\
\hline 119 & Mild & 14 & 7.72 & 37.1 & 36 & $\mathrm{E}, \mathrm{B}, \mathrm{T}, \mathrm{B}, \mathrm{B}, \mathrm{B}, \mathrm{B}, \mathrm{T}, \mathrm{B}, \mathrm{B}, \mathrm{B}, \mathrm{R}, \mathrm{B}, \mathrm{B}$ & -3.42 \\
\hline 195 & Mild & 11 & 8.24 & 41.4 & 54 & $\mathrm{E}, \mathrm{B}, \mathrm{E}, \mathrm{E}, \mathrm{B}, \mathrm{E}, \mathrm{B}, \mathrm{T}, \mathrm{R}, \mathrm{B}, \mathrm{R}$ & 0.45 \\
\hline 50 & Mild & 10 & 6.27 & 43.5 & 70.5 & $B, E, R, B, E, B, B, B, B, R$ & -2.27 \\
\hline 117 & Mild & 20 & 9.72 & 49.6 & 51 & $\begin{array}{l}\mathrm{E}, \mathrm{E}, \mathrm{B}, \mathrm{R}, \mathrm{B}, \mathrm{E}, \mathrm{B}, \mathrm{E}, \mathrm{T}, \mathrm{T}, \mathrm{B}, \mathrm{T}, \mathrm{B}, \mathrm{E}, \mathrm{B}, \mathrm{E}, \mathrm{T}, \\
\mathrm{T}, \mathrm{B}, \mathrm{B}\end{array}$ & -0.31 \\
\hline
\end{tabular}

555 aDisease aggressiveness for each subject was based on publicly available metadata.

$556{ }^{b} \mathrm{~N}$ represents the number of sputum microbiomes available for each subject, observed over the

557 period, given in years.

$558{ }^{\mathrm{c}}$ Clinical states observed: $\mathrm{B}=$ baseline, $\mathrm{E}=$ exacerbation, $\mathrm{T}=$ treatment, $\mathrm{R}=$ Recovery.

559 dinear regression estimates of annual change in FEV1 percent predicted for each subject shown

560 at far right. The table is sorted by increasing median age. 


\section{References}

564

565 1. MacKenzie T, Gifford AH, Sabadosa KA, Quinton HB, Knapp EA, Goss CH,

566 Marshall BC. 2014. Longevity of Patients with Cystic Fibrosis in 2000 to 2010 and Beyond: Survival Analysis of the Cystic Fibrosis Foundation Patient Registry. Ann Intern Med 161:233-241.

Emerson J, Rosenfeld M, McNamara S, Ramsey B, Gibson RL. 2002. Children with Cystic Fibrosis. Pediatr Pulmonol 34:91-100. with Cystic Fibrosis. Chest 149:390-400. 
$583 \quad$ 6. Govan JRW, Nelson JW. 1992. Microbiology of Lung Infection in Cystic Fibrosis. British Medical Bulletin 48:912-930.

585 7. Burns JL, Emerson J, Stapp JR, Yim DL, Krzewinski J, Louden L, Ramsey BW, Clausen CR. 1998. Microbiology of Sputum from Patients at Cystic Fibrosis Centers in the United States. Clinical Infectious Diseases 27:158-163.

$588 \quad 8$.

Saiman L, Siegel J. 2004. Infection Control in Cystic Fibrosis. Clinical Microbiology Reviews 17:57-71. Medical Practice in Cystic Fibrosis: Part II. Use of Therapies. Pediatr Pulmonol 28:248-254. Disease. http://dxdoiorg/102217/174609131153 1:53-61.

595 11. Harris JK, De Groote MA, Sagel SD, Zemanick ET, Kapsner R, Penvari C, Kaess Sci USA 104:20529-20533.

599 12. Filkins LM, Hampton TH, Gifford AH, Gross MJ, Hogan DA, Sogin ML, 600 Morrison HG, Paster BJ, O'Toole GA. 2012. Prevalence of Streptococci and 601 Increased Polymicrobial Diversity Associated with Cystic Fibrosis Patient Stability. Journal of Bacteriology 194:4709-4717. 
603 13. O'Toole GA. 2018. Cystic Fibrosis Airway Microbiome: Overturning the Old, Opening the Way for the New. Journal of Bacteriology 200:344.

605

606

607

608

609

610

611

61216

613

614

615

616

617

618

619
Acosta N, Heirali A, Somayaji R, Surette MG, Workentine ML, Sibley CD, Rabin HR, Parkins MD. 2018. Sputum Microbiota Is Predictive of Long-Term Clinical Outcomes in Young Adults with Cystic Fibrosis. Thorax 73:1016-1025.

15. Zhao J, Schloss PD, Kalikin LM, Carmody LA, Foster BK, Petrosino JF, Cavalcoli JD, VanDevanter DR, Murray S, Li JZ, Young VB, LiPuma JJ. 2012. Decade-Long Bacterial Community Dynamics in Cystic Fibrosis Airways. Proceedings of the National Academy of Sciences 109:5809-5814.

van der Gast CJ, Walker AW, Stressmann FA, Rogers GB, Scott P, Daniels TW, Carroll MP, Parkhill J, Bruce KD. 2011. Partitioning Core and Satellite Taxa from within Cystic Fibrosis Lung Bacterial Communities. The ISME Journal 5:780-791.

17. Cuthbertson L, Walker AW, Oliver AE, Rogers GB, Rivett DW, Hampton TH, Ashare A, Elborn JS, De Soyza A, Carroll MP, Hoffman LR, Lanyon C, Moskowitz SM, O’Toole GA, Parkhill J, Planet PJ, Teneback CC, Tunney MM, Zuckerman JB, Bruce KD, van der Gast CJ. 2020. Lung Function and Microbiota Diversity in Cystic Fibrosis. Microbiome, 4 ed. 8:45-13.

18. Carmody LA, Caverly LJ, Foster BK, Rogers MAM, Kalikin LM, Simon RH, VanDevanter DR, LiPuma JJ. 2018. Fluctuations in Airway Bacterial Communities Associated with Clinical States and Disease Stages in Cystic Fibrosis. PLoS ONE 13:e0194060. 
624 19. Goss CH, Burns JL. 2007. Exacerbations in Cystic Fibrosis · 1: Epidemiology and Pathogenesis. Thorax 62:360-367.

626 20. Flume PA, Peter J Mogayzel J, Robinson KA, Goss CH, Rosenblatt RL, Kuhn RJ, Marshall BC, Committee ATCPGFPT. 2012. Cystic Fibrosis Pulmonary Guidelines. Am J Respir Crit Care Med 180:802-808. Recovery in Health-Related Quality Of Life During and After Pulmonary Exacerbations in Patients with Cystic Fibrosis. Journal of Cystic Fibrosis 18:737-742. Antimicrobial Treatment in Cystic Fibrosis. Pediatr Pulmonol 55:828-834. 
644 25. Sibley CD, Parkins MD, Rabin HR, Duan K, Norgaard JC, Surette MG. 2008. A Polymicrobial Perspective of Pulmonary Infections Exposes an Enigmatic Pathogen in Cystic Fibrosis Patients. Proceedings of the National Academy of Sciences 105: $15070-15075$.

26. Parkins MD, Sibley CD, Surette MG, Rabin HR. 2008. The Streptococcus milleri Group_-An Unrecognized Cause of Disease in Cystic Fibrosis: A Case Series and Literature Review. Pediatr Pulmonol 43:490-497.

651 27. Scott JE, O'Toole GA, Margolin W. 2019. The Yin and Yang of Streptococcus Lung Infections in Cystic Fibrosis: A Model for Studying Polymicrobial Interactions. Journal of Bacteriology 201:15070. Biofilms Microbiomes 2:4-11. with Cystic Fibrosis. J Cyst Fibros. doi: 10.1016/j.jcf.2020.12.022.

\section{30. Hahn A, Burrell A, Fanous H, Chaney H, Sami I, Perez GF, Koumbourlis AC,}


665 31. Coburn B, Wang PW, Caballero JD, Clark ST, Brahma V, Donaldson S, Zhang DS. 2015. Lung Microbiota Across Age and Disease Stage in Cystic Fibrosis. Sci Rep 5:1-12. Intervention. The ISME Journal 10:1081-1091. 18:808-816. 
Lozupone C, Maher M, Marotz C, Martin BD, McDonald D, McIver LJ, Melnik

LF, Orchanian SB, Pearson T, Peoples SL, Petras D, Preuss ML, Pruesse E,

35. Goslee SC, Urban DL. 2007. The Ecodist Package for Dissimilarity-Based Analysis of Ecological Data. Journal of Statistical Software, 22(7):1-19.

$699 \quad 36 . \quad$ Jari Oksanen, F. Guillaume Blanchet, Michael Friendly, Roeland Kindt, Pierre vegan: Community Ecology Package. R package version 2.5-7. https://CRAN.R-

704 37. Kassambara A, Mundt F. 2020. factoextra: Extract and Visualize the Results of 
$707 \quad 38 . \quad$ Andy Liaw and Matthew Wiener. 2002. Classification and Regression By randomForest. R package version 4.6-14. https://CRAN.Rproject.org/package= randomForest version 0.8.5-4. https://CRAN.R-project.org/package=markovchain

712 40. Bray JR, Curtis JT. 1957. An Ordination of the Upland Forest Communities of 713 Southern Wisconsin. Ecological Monographs 27:325-349.

714 41. Namkung J. 2020. Machine Learning Methods for Microbiome Studies. J Microbiol $715 \quad \mathbf{5 8 : 2 0 6 - 2 1 6 . ~}$

716 42. Sneath, P., Sokal, R. 1962. Numerical Taxonomy. Nature. 193: 855-860

717 43. Madan JC, Koestler DC, Stanton BA, Davidson L, Moulton LA, Housman ML, 718 Moore JH, Guill MF, Morrison HG, Sogin ML, Hampton TH, Karagas MR, 719 Palumbo PE, Foster JA, Hibberd PL, O'Toole GA. 2012. Serial Analysis of the Gut and Respiratory Microbiome in Cystic Fibrosis in Infancy: Interaction Between Intestinal and Respiratory Tracts and Impact of Nutritional Exposures. mBio

723 44. Price KE, Hampton TH, Gifford AH, Dolben EL, Hogan DA, Morrison HG, 724 Sogin ML, O'Toole GA. 2013. Unique Microbial Communities Persist in Individual 725 Cystic Fibrosis Patients throughout a Clinical Exacerbation. Microbiome 1:27-1. 
45. Harris JK, Wagner BD, Zemanick ET, Robertson CE, Stevens MJ, Heltshe SL, Ivacaftor Treatment in Patients with Cystic Fibrosis and the G551D Mutation. Annals of the American Thoracic Society 17:212-220.

Tibshirani R, Walther G, Hastie T. 2001. Estimating the Number of Clusters in a (Statistical Methodology) 63:411-423.

Tibshirani R, Walther G. 2012. Cluster Validation by Prediction Strength. Journal of Computational and Graphical Statistics. Occur with Age. The ISME Journal 9:1246-1259. Thorax 67:867-873.

744 50. Zemanick ET, Wagner BD, Robertson CE, Ahrens RC, Chmiel JF, Clancy JP, 
Harris JK. 2017. Airway Microbiota Across Age and Disease Spectrum in Cystic Fibrosis. Eur Respir J 50:1700832.

749 51. Flight WG, Smith A, Paisey C, Marchesi JR, Bull MJ, Norville PJ, Mutton KJ, Webb AK, Bright-Thomas RJ, Jones AM, Mahenthiralingam E, McAdam AJ. 2015. Rapid Detection of Emerging Pathogens and Loss of Microbial Diversity Associated with Severe Lung Disease in Cystic Fibrosis. Journal of Clinical Microbiology 53:2022-2029.

$754 \quad$ 52. Breiman L. 2001. Random Forests. Machine Learning 45:5-32.

$755 \quad$ 53. Conrad DJ, Billings J, Teneback C, Koff J, Rosenbluth D, Bailey BA, Jain R. 756 2021. Multi-Dimensional Clinical Phenotyping of a National Cohort of Adult Cystic 757 Fibrosis Patients. Journal of Cystic Fibrosis 20:91-96.

$758 \quad$ 54. Conrad D, Haynes M, Salamon P, Rainey PB, Youle M, Rohwer F. 2013. Cystic Fibrosis Therapy: A Community Ecology Perspective. Am J Respir Cell Mol Biol

$76155 . \quad$ Muhlebach MS, Zorn BT, Esther CR, Hatch JE, Murray CP, Turkovic L, and Succession of The Cystic Fibrosis Lung Microbiome is Associated with Disease Progression in Infants and Preschool Children. PLoS Pathog 14:e1006798.

765 56. Nelson MT, Wolter DJ, Eng A, Weiss EJ, Vo AT, Brittnacher MJ, Hayden HS, 
Maintenance Tobramycin Primarily Affects Untargeted Bacteria in the CF Sputum

Microbiome. Thorax 75:780-790.

770 57. Heirali AA, Acosta N, Storey DG, Workentine ML, Somayaji R, Laforest

$774 \quad$ 58. Grinwis ME, Sibley CD, Parkins MD, Eshaghurshan CS, Rabin HR, Surette MG. 48:395-401.

$778 \quad 59 . \quad$ Vandeplassche E, Sass A, Ostyn L, Burmølle M, Kragh KN, Bjarnsholt T, Coenye 